Check for updates

The BMJ

Cite this as: BMJ 2021;374:n1822 http://dx.doi.org/10.1136/bmj.n1822 Published: 19 July 2021

\section{Sixty seconds on ... the pingdemic}

\author{
Abi Rimmer
}

\section{Too much ping pong? The new tennis elbow?}

No, this isn't about a boom in lockdown hobbies. We're talking about the rise in the number of people who have been "pinged" and told to self-isolate by the NHS Test and Trace app.

\section{It's bounced up?}

You could say that. Between 1 and 7 July, 520194 people in England received an alert telling them to self-isolate for 10 days. A further 9932 received the same alert in Wales.

\section{Pinging hell!}

Yes, it's a lot. In fact, it's the highest number recorded since January. The previous week, 24 to 30 June, 356 677 people in England and 6959 in Wales received an alert.

\section{In isolation, is this a problem?}

Unfortunately, yes. The sheer number of people being asked to isolate is having an effect on a range of industries, including manufacturing and hospitality. Nick Allen, chief executive of the British Meat Processors Association, for example, has said that some companies might have to "start shutting down production lines."

\section{What about health workers?}

Until very recently, staff were able to pause the app while at work ${ }^{2}$ but if they were pinged because of meeting someone with the virus outside of work they still had to self-isolate. It understandably caused problems. Chris Hopson, chief executive of NHS Providers, said one trust had lost 500 of its staff to self-isolation. ${ }^{3}$

\section{What's 'appened now?}

On 19 July the government announced that doubly vaccinated frontline staff who have been pinged could avoid self-isolation if they had a negative polymerase chain reaction test and had daily negative lateral flow tests for at least seven days. ${ }^{4}$ Their employer can then decide if it's safe for them to work. Danny Mortimer, chief executive of NHS Employers, says that this local discretion is vital as the risks to patients and colleagues need to be balanced with the needs of the service.

\section{Freedom!}

Not quite, staff who are allowed back to work will still be under a legal duty to self-isolate when not at work, and they will continue to receive self-isolation reminders. They are allowed to work because they are considered to have a "reasonable excuse" under the self-isolation regulations-where their absence from work could result in harm.

\section{Can't we just all stop self-isolating?}

No, that would be ignoring the science. According to Simon Clarke, associate professor in cellular microbiology at the University of Reading, while staying at home for 10 days might be a great inconvenience "it is much, much more damaging for people's health and the economy to have a rampant new wave of infections ballooning out of control. Self-isolation is one of the most effective tools we have to prevent spread. As we reopen the economy and society fully, and change rules on home working, mask wearing, and social distancing, it is one of the few effective tools we have left.”

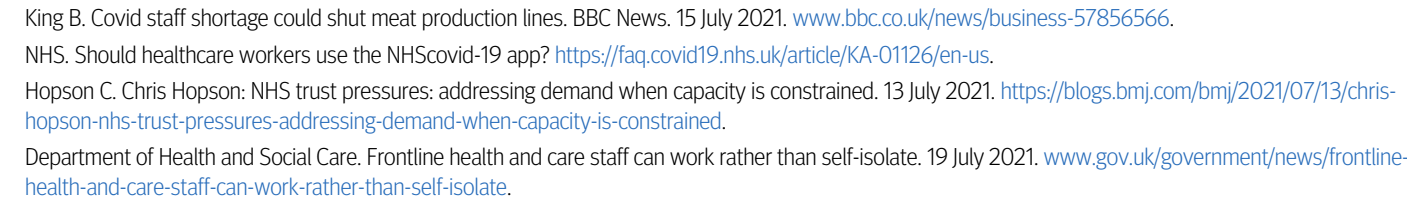

